\title{
Cation Exchange Capacity and Base Saturation Variation among Alberta, Canada, Moss Peats
}

\author{
Janet F.M. Rippy and Paul V. Nelson' \\ Department of Horticultural Science, Box 7609, North Carolina State \\ University, Raleigh, NC 27695
}

Additional index words. Sphagnum species, neutralization requirement, $\mathrm{pH}$ drift

\begin{abstract}
Variations in moss peat cation exchange capacity (CEC) and base saturation (BS) can result in inconsistent initial $\mathrm{pH}$ in moss peat-based substrates created using standard formulas for limestone additions and can lead to subsequent drift from the initial pH in those substrates. This study was conducted to determine the extent of such variation. CEC and BS were measured in three replications on 64 moss peat samples that were selected from three mires across Alberta, Canada, to represent maximum gradients in plant species composition within six degrees of decomposition acceptable for professional peat-based substrates. CEC ranged from 108 to $162 \mathrm{cmol} \cdot \mathrm{kg}^{-1}$ (meq.100 g). Averaged overall samples, BS ranged from $15 \%$ to $71 \%$ of $\mathrm{CEC}$ and calcium accounted for $68 \%$, magnesium for $25 \%$, sodium for $5 \%$, and potassium for $1.4 \%$ of BS. CEC was positively correlated to the amount of Sphagnum fuscum (Schimp.) Klingrr. in the sample $(r=0.22)$. BS was positively correlated to the amount of sedge $(r=0.28)$. Neither $C E C$ nor BS was influenced by degree of decomposition $(r=0.002$ and $r=0.08$, respectively). Moss peats with high CEC have a greater buffering capacity than those with low CEC, resulting in less $\mathrm{pH}$ drift. Moss peats with high $\mathrm{BS}$ should have a low neutralization requirement to achieve a target $\mathrm{pH}$. Understanding the species composition in peat-based substrates can alleviate problems of inconsistent initial $\mathrm{pH}$ and subsequent $\mathrm{pH}$ drift.
\end{abstract}

Growers who formulate their own soilless substrates and companies that sell readymixed soilless substrates face two problems. First, there is difficulty in attaining consistently initial substrate $\mathrm{pH}$ targets using standard formulas for limestone additions. The second problem arises when substrate $\mathrm{pH}$ drifts away from the initial target over the course of production. It is possible that within or among mires from which moss peat is harvested, there may be variation in the amount of "native" acidity to be neutralized and in the buffering capacity of moss peats.

Two factors that may affect the neutralization requirement and buffering capacity of moss peat among batches are cation exchange capacity (CEC) and base saturation [fractional calcium $\left(\mathrm{Ca}^{2+}\right)$, magnesium $\left(\mathrm{Mg}^{2+}\right)$, potassium $\left(\mathrm{K}^{+}\right)$, and sodium $\left.\left(\mathrm{Na}^{+}\right)\right]$ (BS). These properties may be related to the composition of plant species in each pro-

\footnotetext{
Received for publication 9 Sept. 2006. Accepted for publication 14 Nov. 2006.

We thank the North Carolina Agricultural Research Service (NCARS), Raleigh, NC, for support; Sun Gro Horticulture, Bellevue, Wash., for support and provision of moss peat samples; and Jean MacDonald of Highland Grey Co. Alberta, Canada, for determination of species composition and degree of decomposition of said samples.

Use of trade names in the publication does not imply endorsement by the NCARS of products named nor criticism of similar ones not mentioned. ${ }^{1}$ To whom reprint requests should be addressed; e-mail paul_nelson@ncsu.edu.
}

cessed batch of peat. The physical and chemical properties differ among the three types of peat commonly found in horticultural substrates: reed sedge (Carex sparganioides Muhl ex Willd), Hypnum species, and Sphagnum moss peats (Argo and Biernbaum, 1997; Bunt, 1988; Nelson, 2002; Puustjarvi and Robertson, 1975). Of these three types of peat, Sphagnum has been thought to be highly consistent and consequently and is used most extensively.

Only three of the 14 species of Sphagnum are used in commercial peat-based substrates: S. angustifolium (Russow) C. Jens, S. fuscum (Schimp.) Klingrr., and S. magellanicum Brid. The occurrence and growth habits of these Sphagnum species may cause inherent CEC and BS to vary.

Du Rietz (1949, 1954) described the relationship between trophic status and vegetation and distinguished between fens and bogs within mires. Fens are differentiated from bogs when $\mathrm{pH}$, higher cation concentrations, and higher electrical conductivity (EC) indicate plant contact with mineral soil water (Horton et al., 1979). Therefore, fen vegetation is considered to be minerotrophic. By definition, bogs are not influenced by water that is in contact with mineral soils. Rather, the moisture in a bog is derived solely from precipitation; thus, bog vegetation is ombrotrophic (Horton et al., 1979).

Across Canada, trophic gradients range from ombrotrophic conditions in the treedtundra, where vegetation is elevated above the water table by permafrost, to very poorly minerotrophic conditions in thaw pockets (isolated areas of thawed ground) characterized by $\mathrm{pH} 3.3$ to $4.1, \mathrm{Ca}^{2+}$ from 0.01 to 0.14 $\mathrm{mol} \cdot \mathrm{L}^{-1}, \mathrm{Mg}^{2+}$ from 0.0004 to 0.0123 $\mathrm{mol} \cdot \mathrm{L}^{-1}$, and EC from 9.2 to $36.1 \mu \mathrm{mho} \cdot \mathrm{cm}^{-1}$ $(1 \mu \mathrm{mho}=1 \mu \mathrm{S})$ to more highly minerotrophic conditions along streams in which $\mathrm{pH}$ ranges from 4.8 to $5.1, \mathrm{Ca}^{2+}$ from 0.157 to $0.162 \mathrm{~mol} \cdot \mathrm{L}^{-1}, \mathrm{Mg}^{2+}$ from 0.008 to 0.012 $\mathrm{mol} \cdot \mathrm{L}^{-1}$, and EC from 35.6 to 41.9 $\mu \mathrm{mho} \cdot \mathrm{cm}^{-1}$ (Horton et al., 1979).

The three species of Sphagnum used for horticultural purposes exist in distinct strata with respect to the water table (Bragazza and Gerdol, 1999; Mulligan and Gignac, 2001). Sphagnum angustifolium is a dominant species in poor (slightly minerotrophic) fens; however, it becomes sporadic and scarce in calcareous regions. It typically occurs in hollows below S. magellanicum in weakly to moderately minerotropohic habitats (Vitt and Andrus, 1977). Sphagnum magellanicum grows in moist habitats but cannot tolerate flooding (Kulczyńsky, 1949). It occurs in the shallower parts of thaw pockets and is found only on the better developed mounds of S. angustifolium (Horton et al., 1979). Sphagnum fuscum most frequently forms islands of ombrotrophic vegetation, occurring on bogs above $S$. magellanicum and $S$. angustifolium (Vitt and Andrus, 1977).

The distinct variation in the $\mathrm{pH}$ of the water among the strata in which these Sphagnum species are found may cause them to differ in BS and CEC, which are influenced by the $\mathrm{pH}$-dependent exchange of cations and hydrogen ions $\left(\mathrm{H}^{+}\right)$from organic acid fundamental groups (Argo and Biernbaum, 1997; Helling et al., 1964; Sumner and Miller, 1996). Because peatmoss is harvested across bogs without respect to speciation, these differences may affect the CEC and BS, hence the neutralization requirement and buffering capacity of the peat used for container substrates among batches. This study was conducted to examine the extent to which variation in CEC and BS exists among peatmosses across three mires in Alberta, Canada.

\section{Methods and Materials}

Much of the moss peat used for commercial soilless substrates in the United States comes from Canadian mires. These bogs are harvested during June, July, and August. The harvested moss is stockpiled in windrows at the edges of the bogs until it is used. In September 2002, one sample was collected from each stockpile of moss peat harvested from three Alberta, Canada, mires, for a total of 465 samples. These samples were analyzed for degree of decomposition according to the von Post (1937) scale (later modified by Puustjarvi and Robertson, 1975) and species composition by means of visual identification by Jean MacDonald (botanist; Highland Grey Co., Alberta, Canada). Of these 465 samples, 64 were selected to encompass a broad range of the three Sphagnum species and sedge composition within each of six decomposition stages: H1.5= almost 
no decomposition to $\mathrm{H} 4$ = slightly decomposed. Moss peat that is more highly decomposed than $\mathrm{H} 4$ is not used for commercial horticultural purposes.

Three samples were randomly chosen from each of the aforementioned 64 to comprise three replications. Cation exchange capacity was measured on $\approx 2$ g of air-dry, ground moss peat in a complete random design using a protocol described by Thorpe (1973). In this procedure, moss peat was soaked in $100 \mathrm{~mL}$ half-normal hydrochloric acid $(0.5 \mathrm{~N} \mathrm{HCl})$ to displace the adsorbed cations and saturate the moss peat exchange sites with $\mathrm{H}^{+}$. The suspension was filtered through coarse, fast filter paper and the displaced cations were removed with three successive washes of deionized water (100 $\mathrm{mL}$ each). The $\mathrm{HCl}$ filtrate and wash filtrates were combined for each sample and the resulting solutions were reserved for later analysis of cation concentration. After the third wash, the moss peat was soaked in $100 \mathrm{~mL}$ barium acetate $\left[0.5 \mathrm{~N} \mathrm{Ba}(\mathrm{OAc})_{2}\right]$, which displaced the $\mathrm{H}^{+}$by saturating the exchange sites with barium $\left(\mathrm{Ba}^{2+}\right)$. This suspension was filtered and the moss peat was washed three more times with $100 \mathrm{~mL}$ deionized water for each wash to remove the displaced $\mathrm{H}^{+}$. The combined $\mathrm{Ba}(\mathrm{OAc})_{2}$ filtrate + wash filtrates solution was collected for each sample and titrated with sodium hydroxide $(0.1 \mathrm{~N} \mathrm{NaOH})$ to a phenolphthalein end point $(\mathrm{pH} \approx 8.0)$. Cation exchange capacity was calculated from the amount of titrant used and expressed as $\mathrm{cmol} \cdot \mathrm{kg}^{-1}\left(\mathrm{cmol} \cdot \mathrm{kg}^{-1}=\mathrm{meq} \cdot 100 \mathrm{~g}\right)$.

The first solution was analyzed for concentrations of $\mathrm{Ca}^{2+}, \mathrm{Mg}^{2+}, \mathrm{K}^{+}$, and $\mathrm{Na}^{+}$using atomic absorption spectrometry (PerkinElmer Lambda 3 ultraviolet/DIS spectrophotometer, Oak Brook, Ill.). Standard curves were generated to convert absorbance readings to $\mathrm{mg} \cdot \mathrm{L}^{-1}$. Measured cation concentrations were calculated and expressed as $\mathrm{cmol} \cdot \mathrm{kg}^{-1}$. Base saturation as a percentage of CEC was calculated by dividing the sum of the cation concentrations by the CEC and multiplying by 100 . Moisture content of the air-dry moss peat samples was determined at the time CEC was measured. All data were standardized to an oven-dry basis.

Cation exchange capacity and BS data were analyzed by an analysis of variance using the ANOVA procedure of SAS (SAS Inst., Cary, N.C.) for differences among the 64 moss peat samples. Means were separated by Tukey's honest significant difference (HSD) at $\alpha=0.05$. Degree of decomposition, species distribution, and measured cation concentrations $\left(\mathrm{cmol} \cdot \mathrm{kg}^{-1}\right)$ were included in a correlation analysis using the CORR procedure of SAS (SAS Inst.) to determine the extent to which they were related to CEC and BS.

\section{Results and Discussion}

Averaged over three replications, CEC ranged from $108 \pm 7$ to $162 \pm 23 \mathrm{cmol} \cdot \mathrm{kg}^{-1}$ with the mean value of all 64 samples being $139 \pm 15 \mathrm{cmol} \cdot \mathrm{kg}^{-1}$ (Fig. 1). Inherent base saturation for the moss peats ranged from

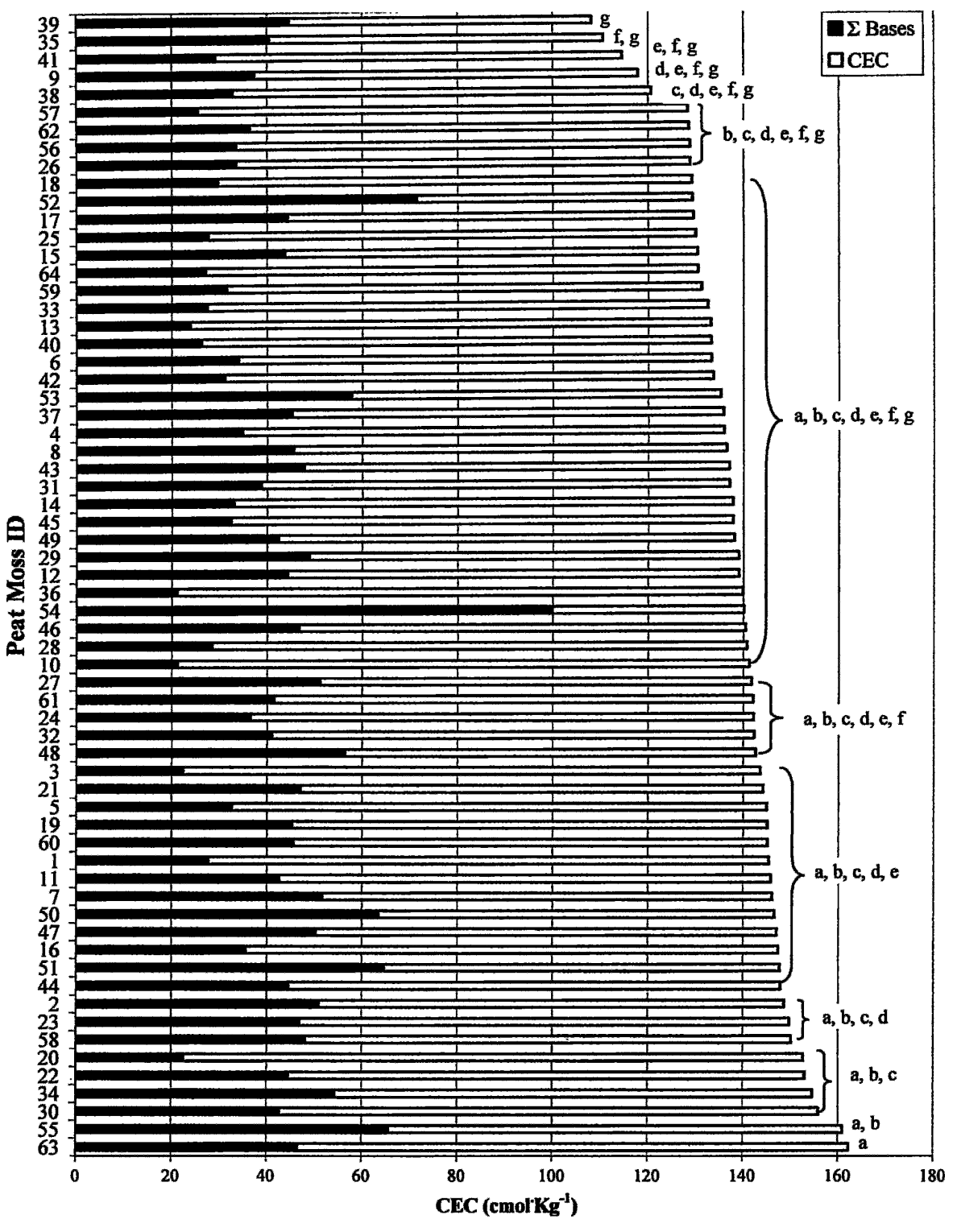

Fig. 1. Cation exchange capacities (CEC) and the sum of the basic cations calcium, magnesium, potassium, and sodium for 64 peatmoss samples from three mires in Alberta, Canada. Significant differences in CEC are denoted by different letters. Tukey's honest significant difference (HSD) $0.05=343.19$.

$15 \pm 4 \%$ to $71 \pm 6 \%$ of CEC. The mean BS was $30 \pm 11 \%$ CEC. Both CEC and BS varied significantly among moss peats with the lowest and the highest values; however, there was considerable overlap among both measurements of the remaining moss peat samples.

Puustjarvi and Robertson (1975) reported a range of CEC values in relation to degree of decomposition from $100 \mathrm{cmol} \cdot \mathrm{kg}^{-1}$ for $\mathrm{H} 1$ moss peats to $124 \mathrm{cmol} \cdot \mathrm{kg}^{-1}$ for $\mathrm{H} 5$ moss peats. Cowan (2005) described organic soils as those that are mostly comprised of moss peat. He provided a CEC range from 150 to $200 \mathrm{cmol} \cdot \mathrm{kg}^{-1}$ in newly formed organic soils. Although there is some variation in the published CEC values, those obtained in this study are in accordance with the literature. Base saturation values are compatible with the findings of Cowan (2005), who states that peat soils can be up to $50 \%$ base-saturated.

The basic cation concentrations as a percentage of BS were within previously reported ranges except $\mathrm{Na}^{+}$, which was only slightly higher (Fig. 2). Calcium accounted for the largest portion of BS. Bunt (1988) states that the high CEC of peat (as opposed to mineral soils) indicates the potential for greater adsorption of divalent cations $\left(\mathrm{Ca}^{2+}\right.$ and $\left.\mathrm{Mg}^{2+}\right)$, whereas most of the monovalent cations $\left(\mathrm{K}^{+}\right.$and $\left.\mathrm{Na}^{+}\right)$remain water-soluble. One divalent cation will displace two $\mathrm{H}^{+}$. Thus, divalent basic cations will neutralize acid more efficiently than monovalent cations. Additionally, $\mathrm{Ca}^{2+}$ and $\mathrm{Mg}^{2+}$ are weakly complexed with carboxyl groups, making them readily exchangeable with $\mathrm{H}^{+}$(Broadbent and Ott, 1957).

The variation in BS occurred independently of CEC (Fig. 1). Although moss peat samples varied in the amount of exchange sites, they also varied in the amount of associated bases. These variations are the result of the composition of Sphagnum species in the moss peat samples (Fig. 3). Moss 
peat samples with high CEC contained larger amounts of $S$. fuscum than samples with low CEC.

In Table 1, the Pearson correlation coefficients for the relationships of CEC, BS, degree of decomposition, species composition, and measured cation concentrations are listed along with associated $P$ values. From this table, CEC was significantly correlated to S. fuscum; however, BS was most highly correlated to sedge. Sphagnum fuscum is ombrotrophic vegetation having no contact with soil surface water; thus, it would have few associated cations other than $\mathrm{H}^{+}$.

As mentioned earlier, Puustjarvi and Robertson (1975) found CEC varied with the degree of decomposition. It seems reasonable that as the moss peat decomposes, there

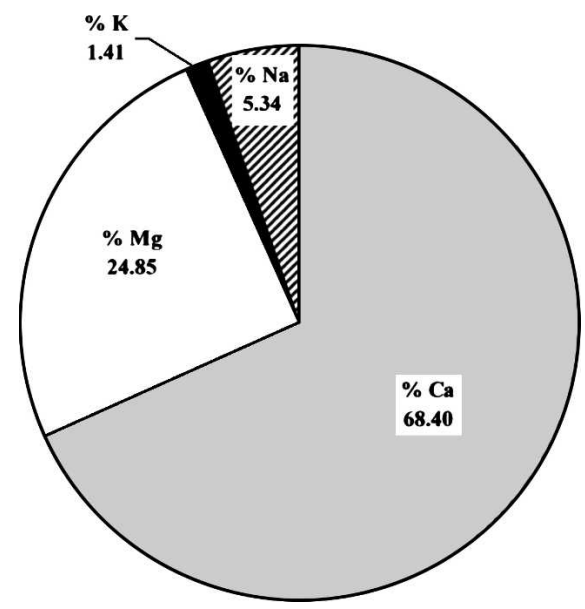

Fig. 2. Basic cations as a percentage of the base saturation averaged over 64 peatmoss samples from three mires in Alberta, Canada. Ranges of bases: calcium $57.06 \%$ to $82.09 \%$, magnesium $13.66 \%$ to $38.06 \%$, potassium $0.26 \%$ to $5.50 \%$, and sodium $1.66 \%$ to $11.61 \%$. would be more ionizable organic acid functional groups exposed. This study encompassed about the same species distribution within each degree of decomposition. The lack of significant correlation between CEC and decomposition in these findings may be explained by the relationship of CEC to species distribution.

Because of the minerotrophic habitats of $S$. angustifolium and S. magellanicum, it may be intuitive to presume that greater extractable $\mathrm{Ca}^{2+}$ and $\mathrm{Mg}^{2+}$ would be associated with these species than with ombrotrophic
S. fuscum. In this study, although the correlation was not strong, extractable $\mathrm{Ca}^{2+}$ and $\mathrm{Mg}^{2+}$ are positively correlated to $S$. fuscum and negatively correlated to the other two Sphagnum species. First, the CEC is much higher in S. fuscum than in the other two species, allowing cations to be present in greater concentrations on S. fuscum. Second, although $S$. fuscum is found in ombrotrophic, rather than minerotrophic habitats, the samples examined here were taken from stockpiles of harvested peatmoss. The cations other than $\mathrm{H}^{+}$associated with $S$. fuscum were probably

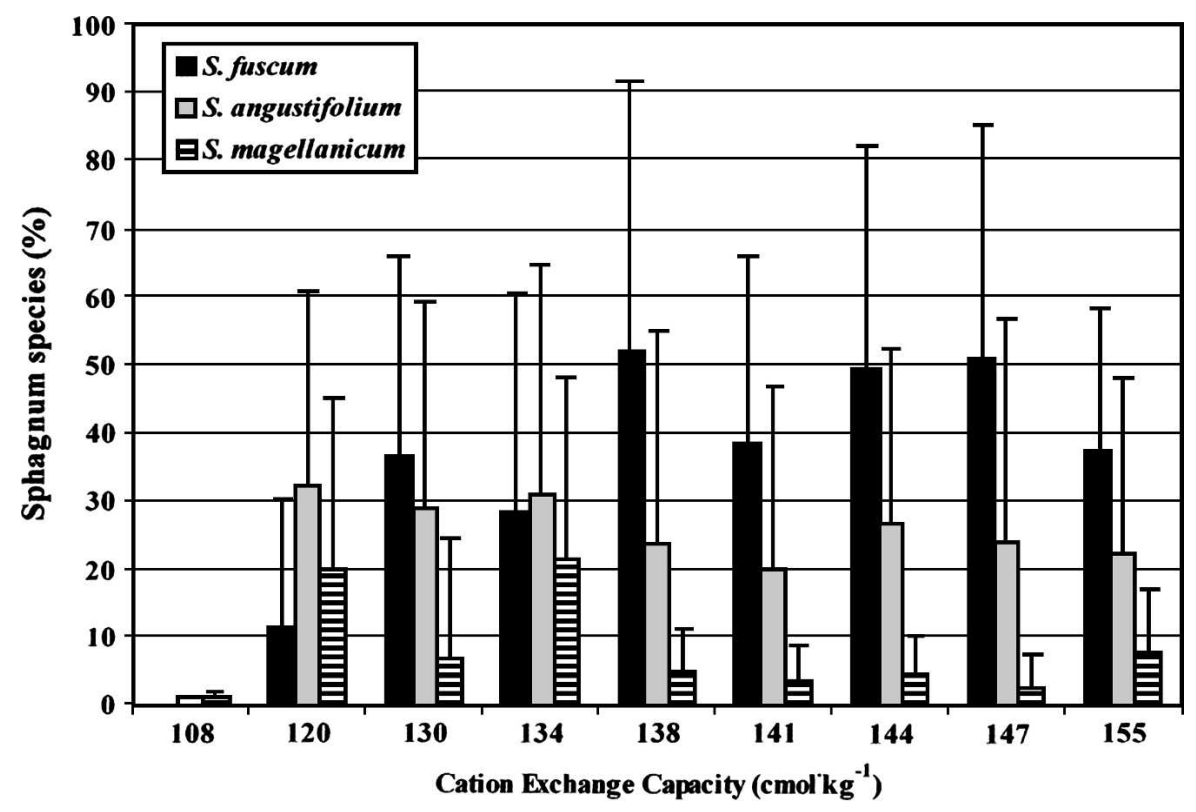

Fig. 3. Cation exchange capacities $\left[(\mathrm{CEC}) \mathrm{cmol} \cdot \mathrm{kg}^{-1}\right]$ of peatmoss samples with varying amounts of three Sphagnum species. A total of 64 peatmoss samples were evaluated. For ease of viewing trends, the sample with the lowest CEC, followed by the average of groups of eight samples-ordered sequentially by increasing $\mathrm{CEC}$ - are depicted. Standard error bars represent variation among CEC groups.

Table 1. Pearson correlation coefficients for the relationships among cation exchange capacity $\left(\mathrm{cmol}^{\circ} \mathrm{kg}^{-1}\right)$, base saturation $(\%$ CEC), degree of decomposition, percent peatmoss species in samples, and measured cation concentrations $\left(\mathrm{mg} \cdot \mathrm{g}^{-1}\right) \mathrm{.}^{\mathrm{z}}$

\begin{tabular}{|c|c|c|c|c|c|c|c|c|c|c|c|}
\hline & \multirow[b]{2}{*}{$\mathrm{CEC}$} & \multirow[b]{2}{*}{ BS } & \multirow[b]{2}{*}{ Decomposition } & \multicolumn{3}{|c|}{ Sphagnum species } & \multirow[b]{2}{*}{ Sedge } & \multirow[b]{2}{*}{ Calcium } & \multirow[b]{2}{*}{ Magnesium } & \multirow[b]{2}{*}{ Potassium } & \multirow[b]{2}{*}{ Sodium } \\
\hline & & & & Fuscum & Angustifolium & Magellanicum & & & & & \\
\hline \multirow[t]{2}{*}{$\overline{\mathrm{CEC}}$} & 1.00000 & 0.02367 & 0.00198 & 0.22272 & -0.04927 & -0.23581 & -0.08462 & 0.25483 & 0.31595 & -0.04133 & 0.22133 \\
\hline & & 0.7445 & 0.9782 & 0.0019 & 0.4973 & 0.0010 & 0.2432 & 0.0004 & $<0.0001$ & 0.5692 & 0.0020 \\
\hline \multirow[t]{4}{*}{ BS } & 0.02367 & 1.00000 & 0.07827 & 0.14124 & -0.33498 & -0.15886 & 0.27744 & 0.95122 & 0.69705 & 0.27240 & 0.14106 \\
\hline & 0.7445 & & 0.2806 & 0.0507 & $<0.0001$ & 0.0277 & $<0.0001$ & $<0.0001$ & $<0.0001$ & 0.0001 & 0.0510 \\
\hline & 0.00198 & 0.07827 & 1.00000 & -0.23922 & -0.11767 & -0.10291 & 0.18928 & 0.10105 & -0.07213 & 0.10526 & -0.08675 \\
\hline & 0.9782 & 0.2806 & & 0.0008 & 0.1040 & 0.1555 & 0.0086 & 0.1631 & 0.3201 & 0.1462 & 0.2315 \\
\hline \multirow[t]{2}{*}{ S. fuscum } & 0.22272 & 0.14124 & -0.23922 & 1.00000 & -0.52097 & -0.31724 & -0.36107 & 0.17467 & 0.35257 & -0.01055 & -0.01890 \\
\hline & 0.0019 & 0.0507 & 0.0008 & & $<0.0001$ & $<0.0001$ & $<0.0001$ & 0.0154 & $<0.0001$ & 0.8846 & 0.7947 \\
\hline \multirow[t]{2}{*}{ S. angustifolium } & -0.04927 & -0.33498 & -0.11767 & -0.52097 & 1.00000 & -0.00193 & -0.42477 & -0.32014 & -0.30135 & 0.11409 & 0.04064 \\
\hline & 0.4973 & $<0.0001$ & 0.1040 & $<0.0001$ & & 0.9788 & $<0.0001$ & $<0.0001$ & $<0.0001$ & 0.1151 & 0.5757 \\
\hline \multirow[t]{2}{*}{ S. magellanicum } & -0.23581 & -0.15886 & -0.10291 & -0.31724 & -0.00193 & 1.00000 & -0.17929 & -0.23305 & -0.21674 & -0.00492 & -0.04239 \\
\hline & 0.0010 & 0.0277 & 0.1555 & $<0.0001$ & 0.9788 & & 0.0128 & 0.0011 & 0.0025 & 0.9461 & 0.5594 \\
\hline \multirow[t]{2}{*}{ Sedge } & -0.08462 & 0.27744 & 0.18928 & -0.36107 & -0.42477 & -0.17929 & 1.00000 & 0.25295 & 0.06480 & -0.17770 & 0.03322 \\
\hline & 0.2432 & $<0.0001$ & 0.0086 & $<0.0001$ & $<0.0001$ & 0.0128 & & 0.0004 & 0.3718 & 0.0137 & 0.6474 \\
\hline \multirow[t]{2}{*}{$\mathbf{C a}$} & 0.25483 & 0.95122 & 0.10105 & 0.17467 & -0.32014 & -0.23305 & 0.25295 & 1.00000 & 0.68592 & 0.27352 & 0.09768 \\
\hline & 0.0004 & $<0.0001$ & 0.1631 & 0.0154 & $<0.0001$ & 0.0011 & 0.0004 & & $<0.0001$ & 0.0001 & 0.1777 \\
\hline \multirow[t]{2}{*}{ Mg } & 0.31595 & 0.69705 & -0.07213 & 0.35257 & -0.30135 & -0.21674 & 0.06480 & 0.68592 & 1.00000 & 0.01856 & 0.26509 \\
\hline & $<0.0001$ & $<0.0001$ & 0.3201 & $<0.0001$ & $<0.0001$ & 0.0025 & 0.3718 & $<0.0001$ & & 0.7984 & 0.0002 \\
\hline \multirow[t]{2}{*}{$\mathbf{K}$} & -0.04133 & 0.27240 & 0.10526 & -0.01055 & 0.11409 & -0.00492 & -0.17770 & 0.27352 & 0.01856 & 1.00000 & -0.08419 \\
\hline & 0.5692 & 0.0001 & 0.1462 & 0.8846 & 0.1151 & 0.9461 & 0.0137 & 0.0001 & 0.7984 & & 0.2457 \\
\hline \multirow[t]{2}{*}{$\mathbf{N a}$} & 0.22133 & 0.14106 & -0.08675 & -0.01890 & 0.04064 & -0.04239 & 0.03322 & 0.09768 & 0.26509 & -0.084190 & 1.0000 \\
\hline & 0.0020 & 0.0510 & 0.2315 & 0.7947 & 0.5757 & 0.5594 & 0.6474 & 0.1777 & 0.0002 & 0.2457 & \\
\hline
\end{tabular}

${ }^{\mathrm{z}} \mathrm{Absolute}$ values of coefficients range from 0 to 1 with 1 indicating the strongest possible relationship. 
exchanged from other species with lower CEC. Because $\mathrm{Ca}^{2+}$ exerts a significant, positive influence on CEC and BS (Table 1 ), it may be interesting to study these relationships with greater depth than was feasible in this research.

\section{Conclusions}

Moss peat samples varied significantly in $\mathrm{CEC}$ and BS. The variation was the result of the species composition of the samples. Cation exchange capacity appears to be a value that is fundamental to the peatmoss plants and varies by species. The influence of species on $\mathrm{BS}$ is related to $\mathrm{Ca}^{2+}$ and $\mathrm{Mg}^{2+}$ associated with the moss. Cation exchange capacity and BS are independent properties, but they both are highly influenced by $\mathrm{Ca}^{2+}$.

Because $\mathrm{Ca}^{2+}$, a basic cation, comprises the majority of $\mathrm{BS}$, it is reasonable to assume that moss peats with a high BS will have a lower neutralization requirement than those with a low BS. Variations of initial $\mathrm{pH}$ of peat-based substrates among batches may largely be incited by variations in inherent $\mathrm{pH}$ of the moss peat that is used. Formulators of these substrates could reduce this variation by measuring the moss peat BS and adjusting the amount of added limestone accordingly.

Moss peats with a high CEC have a greater ability to exchange cations with $\mathrm{H}^{+}$, allowing for a greater buffering capacity than those with low CEC. Greater buffering capacity results in less $\mathrm{pH}$ drift. CEC is highly correlated to the amount of $S$. fuscum in a batch of moss peat being processed into substrates at any given time. Controlling the amount of S. fuscum may reduce the $\mathrm{pH}$ drift over time that plagues growers and sometimes results in litigation. Further studies are needed to determine the amount of $S$. fuscum required and also to discover whether there are other inherent properties that affect the neutralization requirement of moss peat.

\section{Literature Cited}

Argo, W.R. and J.A. Biernbaum. 1997. The effect of root media on root-zone $\mathrm{pH}$, calcium, and magnesium management in containers with impatiens. J. Amer. Soc. Hort. Sci. 122:275-284.

Bragazza, L. and R. Gerdol. 1999. Hydrology, groundwater chemistry and peat chemistry in relation to habitat conditions in a mire on the South-eastern Alps of Italy. Plant Ecol. 2:243-256.

Broadbent, F.E. and J.B. Ott. 1957. Soil organic matter complexes: I. Factors affecting retention of various cations. Soil Sci. 83:419-428.

Bunt, A.C. 1988. Media and mixes for containergrown plants. Unwin Hyman, London.

Cowan, D. 2005. Measure and manage organic soils. 5 Jan. 2004. <http://www.agtest.com/ articles/Organic_soils.htm>.

Du Rietz, G.E. 1949. Huvudenheter och huvudgränser i svensk myrvegetation. Svensk. Bot. Tidskr. 43:274-309.

Du Rietz, G.E. 1954. Die Mineralbodenwasserzeigergrenze als grundlage einer naturlichen zweigliederung der Nord- und Mitteleuropaischen Moore. Vegetatio 5-6:571-585.
Helling, C.S., G. Chesters, and R.B. Corey. 1964. Contribution of organic matter and clay to soil cation-exchange capacity as affected by the $\mathrm{pH}$ of the saturating solution. Soil Sci. Soc. Amer. Proc. 28:517-520.

Horton, D.G., D.H. Vitt, and N.G. Slack. 1979. Habitats of circumboreal-subarctic sphagna: I. A quantitative analysis and review of species in the Caribou Mountains, northern Alberta. Can. J. Bot. 57:2283-2317.

Kulczyńsky, S. 1949. Peat bogs of Polesie. Mem. Acad. Polon. Sci. Classe Sci. Math. Nat. Sér. B. 15:1-356.

Mulligan, R.C. and L.D. Gignac. 2001. Bryophyte community structure in a boreal poor fen: Reciprocal transplants. Can. J. Bot. 79:404411.

Nelson, P.V. 2002. Greenhouse operations and management. 6th Ed. Prentice Hall, Englewood Cliffs, N.J.

Puustjarvi, V. and R.A. Robertson. 1975. Physical and chemical properties, p. 23-38. In: D.W. Robinson and J.G.D. Lamb (eds.). Peat in horticulture. Academic, London.

Sumner, M.E. and W.P. Miller. 1996. Cation exchange capacity and exchange coefficients, p. 1202-1229. In: D.L. Sparks (ed.) Methods of soil analysis. Part 3-Chemical methods. Soil Sci. Soc. Amer. Book Series No. 5, Madison, Wis.

Thorpe, V.A. 1973. Collaborative study of the cation exchange capacity of peat materials. J. Assn. Anal. Chem. (AOAC) 56:154-157.

Vitt, D.H. and R.E. Andrus. 1977. The genus Sphagnum in Alberta. Can. J. Bot. 55:331357.

von Post, L. 1937. The geographical survey of Irish bogs. Ir. Nat. J. 6:210-277. 